\title{
Imago: el cine en la educación e investigación jurídica
}

\author{
Adriana María Ruiz Gutiérrez. \\ Doctorado en curso en Derecho de la Universidad Santo Tomás, Bogotá (Colombia). Magíster en Filosofía \\ contemporánea, Univesidad de Antioquia. Especialista en Derecho Administrativo. Abogada con estudios en Filosofía \\ y Letras. Docente-investigadora de la Facultad de Derecho de la Universidad Santo Tomás, Medellín. Grupo \\ Interinstitucional e Interdisciplinario de investigación sobre Conflictos y Violencias en su línea sobre Violencia y \\ Construcción de Paz, Universidad de Antioquia-Universidad Santo Tomás, Medellín (Colombia). \\ E-mail: adrianamaruiz@gmail.com
}

A Carlos Enrique Restrepo, por su defensa de la libre investigación.

A Leidy, Melissa y Alex, por la esperanza que nos produce su juventud.

\begin{abstract}
Resumen
El saber jurídico nos exige cada vez más la renovación de sus teorías, categorías y problemas a fin de comprender y transformar nuestra época. Esta generación de un nuevo saber se logra únicamente a partir de la asunción de otras formas de educación e investigación distintas a las meramente lógicas y normativas. En este sentido, el cine constituye una propuesta que aspira a otros modos de comprensión más humanos, heterodoxos y abiertos en relación con las dinámicas sociales, pues se sirve más de la imaginación, las emociones y la solidaridad que de los cálculos de la razón. La afectación artística — en términos de belleza, indignación y repugnancia - constituye una condición necesaria para la educación en tiempos de oscuridad y de barbarie. Las imágenes no deben estar aisladas de la educación; forman parte de la misma bajo esquemas más amplios que la mera repetición literal e irreflexiva de las normas y los procedimientos, por la sencilla razón de que el cine como pensamiento en imágenes es inseparable del resto de la vida.
\end{abstract}

Palabras Clave: Enseñanza del Derecho, Epistemología Anarquista, Cine, Libertad, Imaginación, Solidaridad.

\begin{abstract}
The legal knowledge increasingly requires us to renew their theories, categories and problems in order to understand and transform our time. This generation of new knowledge comes only from taking other forms of education and research than purely logical and regulations. In this sense, the film is a proposal that aims to other modes of human understanding, unorthodox and open regarding social dynamics, as it serves more than the imagination, the emotions and the solidarity of the calculations of reason. Artistic involvement, in terms of beauty, anger and disgust is a necessary condition for education in times of darkness and barbarism: the images should not be isolated from education. They are part of the same broader schemes under which the mere literal, unthinking repetition of rules and procedures, for the simple reason that films like thinking in pictures is inseparable from the rest of life.
\end{abstract}

Keywords: Legal Education, Epistemology Anarchist, Cinema, Freedom, Imagination, Solidarity.

\section{Résumé}

La loi nous oblige à connaître de plus en plus le renouvellement de ses théories, des catégories et des problèmes pour comprendre et transformer notre temps. Cette génération de nouvelles connaissances n'est atteint que de prendre d'autres formes d'éducation et d'autres que la recherche purement logique et politique. En ce sens, le film est une proposition qui vise à d'autres modes de compréhension humaine, orthodoxes et ouvertes dans le cadre de la dynamique sociale, car il sert plus que de l'imagination, les émotions et la solidarité des calculs de la raison. Participation en termes de beauté artistique, la colère et le dégoût est une condition nécessaire pour l'éducation en temps de ténèbres et de barbarie. Les images doivent pas être isolés de l'éducation; partie de celui-ci au titre des régimes plus larges que de simples règles littérales et irréfléchies et des procédures de répétition, pour la simple raison que des films comme la pensée en images est inséparable du reste de la vie.

Mots-clés: Formation Juridique, Anarchiste Epistémologie, Film, Liberté, Imagination, de la Solidarité 



\title{
Imago: el cine en la educación e investigación jurídica*
}

Adriana María Ruiz Gutiérrez

\begin{abstract}
Debemos construir una comunidad de académicos radicales del derecho. Debemos reconocer que trabajamos unos para otros y que trabajamos para el futuro. No carecemos de las herramientas necesarias. Tenemos al alcance de la mano importantísimos elementos de teorización radical sobre todos los aspectos de la vida social. Lo que necesitamos es tener fe, pero no una fe sobre humana. Somos muchos, y producimos a un ritmo febril. Nosotros podemos crear una nueva clase de grupo académico: un grupo que afirme el pensamiento creativo en vez de reprimirlo y que subvierta la jerarquía académica en lugar de someterse a ella o de reproducirla.
\end{abstract}

(Duncan Kennedy, 2012)

En el estado actual de empobrecimiento del hombre y la sociedad hemos preferido la servidumbre a la autonomía de pensar libre y solidariamente nuestra realidad. La sociedad se ha negado indiferentemente a la crítica de aquellos fenómenos de poder, opresión y abandono de la vida humana que, en cambio, parece aceptar sin más. Para la reflexión académica estos problemas se han vuelto, en cambio, inevitables, especialmente para los saberes socio-humanísticos, y entre ellos el jurídico, ya que su sentido se deriva exclusivamente de su relación con la vida humana. En este punto es preciso rememorar la pregunta que define efectivamente gran parte de nuestros actos educativos e investigativos: ¿Qué significa y con qué fin queremos promover una comunidad de pensamiento para pensar desde nosotros mismos, no sólo desde nosotros como individuos, sino también desde nosotros en tanto comunidad? Significa, en primer lugar, una manera de encontrar solidariamente las respuestas a los problemas de nuestra sociedad. Segundo, un ejercicio de pensar desde la amistad académica nuevas formas de alteridad. Tercero, una experiencia del pensamiento,

* El artículo se deriva del proyecto de investigación: El cine como modo de educación jurídica. Grupo Interinstitucional e Interdisciplinario de investigación sobre Conflictos y Violencias en su línea sobre Violencia y construcción de Paz. Universidad Santo Tomás, Medellín. Colombia 
la escucha y la escritura sobre la justicia y la equidad respecto a otros individuos cuyas circunstancias de desarraigo, marginalidad o violencia probablemente no hemos vivido, pero que solidariamente podemos comprender y sentir a partir de la experiencia del dolor. Cuarto, la fidelidad, la confianza, el crédito del compromiso hacia nuestros estudiantes universitarios. La responsabilidad frente a ellos se mide con una cierta cronología, con la prueba de una duración sensible del tiempo a fin de hacernos cada vez más activos y responsables en el acto de pensar nuestra realidad social.

Este presupuesto ético, pero también político, histórico y jurídico, nos demanda un alto compromiso respecto a la educación de nuestros estudiantes. Debemos aportar con todos nuestros medios a que ellos despierten y participen creativamente en la identificación y solución de los problemas sociales. Debemos mostrarles caminos diferentes para que aviven el sentimiento de una comunidad de pensamiento libre, de emancipación y de justicia social, de amistad y de solidaridad. Debemos permitirles comprender que existe algo más que la "obediencia" y "reverencia" a los saberes de sus maestros, que hay valores y experiencias vitales cuyo contenido se afirma desde el propio movimiento del espíritu. En palabras de Walter Benjamin (2010a), debemos cuidar de nuestros estudiantes para que no declinen en su responsabilidad con el presente. Pero ¿Cómo puede un universitario afrontar los problemas más profundos, la miseria de esta sociedad, la guerra, la corrupción, el dolor, sin sucumbir al menos temporalmente a la desperanza? Es preciso que se les oriente críticamente para que sean capaces de despertar a sí mismos y experimentar en su interior el ímpetu que les conduce a pensar en el sufrimiento de los demás. Este hecho debemos sentirlo como un imperativo que nos demanda la educación e investigación jurídica de nuestros estudiantes, a fin de que reconozcan la necesidad de una comprensión y transformación social más humana. En este sentido, la educación ha de otorgarnos una esperanza como posibilidad para el pensamiento y el cambio de nuestro tiempo, no sólo del presente, sino también y más que nada, del tiempo por venir. Con este hacer ético-político en la educación queremos invocar, en última instancia, el privilegio que debe ocupar la vida humana en nuestros actos de pensamiento.

En este examen reside más exactamente la intención de esta propuesta de enseñanza e investigación jurídica al desplazar la pregunta: ¿Qué tipos de conducta humana son imputables jurídicamente?, hacia la pregunta: ¿Cómo se enseña y defiende la condición y la finalidad humana desde la Universidad, especialmente desde las Facultades de Derecho? De esta manera, queremos mostrar la consciencia del valor incondicionado de nuestros estudiantes y la seriedad de sus reflexiones. No queremos que nuestros estudiantes consuman sus posibilidades de comprensión en la indiferencia de la acción y en la placidez de lo dado. No queremos que vegeten en la superficie de un perpetuo olvido de sí mismos y de los otros, en una especie de inercia que los haga instrumentos dóciles de los saberes anquilosados y estériles en su comprensión de la realidad. Queremos proclamar la exigencia de 
nuevas mentalidades universitarias que deben convertirse en la brújula para otras direcciones en el camino del pensar y de la transformación política. De paso, sea este también el motivo para pensar otras concepciones y formas de educación jurídica distintas a aquellas meramente normativas y, sin embargo, no menos importantes, que nos permitan pensar crítica y creativamente los problemas socio-jurídicos.La formación de nuestros estudiantes de derecho a partir de la libertad e imaginación solidaria, constituyen aquí una apuesta epistemológica y metodológica en oposición al dominio saber que se pretende unívoco respecto a los fenómenos y problemas sociales y jurídicos.

\section{EL ANARQUISMO EPISTEMOLÓGICO COMO PROPUESTA PARA LA EDUCACIÓN E INVESTIGACIÓN JURÍDICAS}

Paul Feyerabend defiende la idea de una ciencia anarquista que nos permita examinar críticamente la unidad y la normalización bajo las cuales hemos comprendido nuestras realidades. La ciencia no es absoluta, al contrario, es una entre un sinnúmero de formas de conocimiento humano. De ahí que sus concepciones y reglas sean insuficientes para disponer de ideas generales, coherentes y satisfactorias sobre el mundo de la vida (1986, pp. 12, 167). El anarquismo teórico aparece, en cambio, y según lo expresado por el autor, como una concepción pluralista del mundo a partir de los distintos saberes — naturales, mágicos, religiosos, metafísicos, entre otros - en oposición a los de la razón ilustrada, la cual en su pretensión de universalidad y, en consecuencia, de homogeneidad, ha reducido a la sinrazón otras maneras de conocer y experimentar el mundo. En este sentido, Feyerabend propone la metodología pluralista como una forma de hacer proliferar otras teorías capaces de explicar el mundo. El principio de proliferación es también parte esencial de una perspectiva humanitaria: "los educadores progresistas han intentado siempre desarrollar la individualidad de sus alumnos y procurando que no se pierdan los talentos y creencias particulares y a veces únicos que cada niño posee" (Feyerabend, 1986, p. 24). Defender el intercambio entre la ciencia y las demás concepciones no cientificas derivadas de las experiencias humanas, se nos exige entonces como una medicina más humana y creativa para transformar la unidad indiferenciada y mecánica de nuestros dogmas, tradiciones y pautas de estandarización social. Esta tarea del orden epistemológico, pero también y con mayor razón, del orden político, implica al mismo tiempo una afirmación de las vidas humanas y de la felicidad humana e incluye por tanto una manera de ver radicalmente nueva los hechos, los problemas y los compromisos de nuestro tiempo.

La vida humana acontece en virtud de un conjunto de ideologías que se disputan la verdad de las realidades sociales. La ciencia es una entre variadas ideologías que prefieren la verdad en lugar de la libertad de pensamiento: "en términos de elección, la verdad en la ciencia ha prevalecido sobre la libertad e independencia intelectual; 
no obstante, la elección inversa es posible: podemos abandonar la libertad, pero también podemos abandonar la verdad" (Feyerabend, 1975, p. 158). La ciencia procede reuniendo hechos e infiriendo teorías a partir de ellos. En estricto sentido lógico, las teorías nunca se siguen de los hechos: los convencionalistas e idealistas afirmaron esta realidad al señalar que las teorías únicamente otorgan forma y orden a los hechos científicos o sociales, de lo que procede su conservación. En este punto reside justamente el problema de la ciencia en su pretensión de adquirir la verdad, ya que las teorías científicas asumen para la mente humana un patrón de regularidad. En abierta oposición, Feyerabend (1975) entiende que: "el conocimiento es un océano de alternativas canalizadas y subdivididas por un océano de estándares. Este obliga a nuestra mente a hacer elecciones imaginativas y así la hace crecer, la hace capaz de elegir, imaginar, criticar" (p. 159). El mundo es siempre una entidad desconocida para el individuo y el colectivo social, el cual les exige una apertura permanente. Los individuos se ubican aquí como exploradores que desean descubrir y habitar el mundo sin las leyes y obligaciones impuestos por el cálculo de la razón cartesiana.

Entre los propósitos de Feyerabend (2001) se encuentra, pues, el de defender a la sociedad de la comprensión de la ciencia como ideología totalizante, es decir, como un sistema de ideas ordenadas que pretenden la homogeneidad de todo el saber humano:

Toda ideología debe ser vista en perspectiva. Uno no las debe tomar demasiado en serio. Debe leerlas como (se leen) los cuentos de hadas, los que tienen un montón de cosas interesantes que decir, pero que contienen también maliciosas mentiras, o (leerlas) como prescripciones éticas que pueden ser útiles como reglas prácticas, pero que son mortíferas cuando se las sigue al pie de la letra (Feyerabend, 2001, p. 156).

Esta referencia resulta paradójica si se tienen en cuenta que la ciencia como ideología e instrumento de ilustración en los siglos XVII y XVIII permitió la liberación del hombre de las antiguas y las rígidas creencias basadas en la superstición y el control de la mente humana. Sin embargo, más adelante la ciencia como ideología se constituyó en un modo igualmente opresivo y rígido respecto al saber. Basta con observar, dice Feyerabend (2001), el rol que ocupa la ciencia en la educación: "Los "hechos" científicos son enseñados en una edad muy temprana en la misma forma en que los "hechos" religiosos lo eran hace un siglo". En consecuencia: "No se hace ningún intento por despertar las capacidades críticas del estudiante de modo que pueda ver las cosas en perspectiva. En las universidades la situación es incluso peor, pues el adoctrinamiento es aquí llevado de una manera mucho más sistemática" (Feyerabend, 2001, p. 156). La educación científica, como la entendemos actualmente, apunta cada vez más a la restricción hiperespecializada de las áreas de investigación y, por tanto, de las fuentes y actores que participan en la construcción del conocimiento social, especialmente, y con mayor inquietud, en el conocimiento universitario. Cada dominio del saber se separa, excluye y distancia no sólo de los demás, sino de su propia historia, concentrándose en el dominio de su 
objeto "científico": la física, por ejemplo, se separa de la metafísica y de la teología y recibe una lógica propia (Trigo, Gil da Costa, Pazos; 1986, p. 3). Lo mismo ocurre en el derecho, el cual se distancia del mito, la teología, la literatura, la filosofía, la política que, no sobra decirlo, dada su obviedad, construyeron y dominaron los grandes paradigmas del iusnaturalismo y el iuspositivismo en sus distintas vertientes desde el siglo V hasta el siglo XIX, incluso en la actualidad.

La educación científica también divide fronterizamente sus dominios de aquellos resultados de la pluralidad social y de sus distintos actores: distingue los actores científicos de los profanos, los capitales del saber académico de los vulgares, los campos universitarios de los sociales. La preferencia por la verdad pura, estable y normalizadora nos haría, sin embargo, declinar de aquellos hechos y categorías si los observáramos cuidadosamente en virtud de las vicisitudes y transformaciones de la historia social. Una parte esencial en la renovación de nuestras comprensiones y procedimientos científicos consiste, pues, en hacer borrosas las divisiones entre la educación científica y la sociedad y, en última instancia, entre la verdad y la libertad de pensamiento a partir de la asunción de otros saberes (Feyerabend, 1986, p. 4). La comprensión de esta propuesta epistemológica nos invita a preguntar con Feyerabend:

¿La ideología de la ciencia debe ser impuesta a todo el mundo? ¿No parece más bien que hay que conceder a las tradiciones que dan sentido a la vida de las personas iguales derechos e igual acceso a los principales puestos de la sociedad con independencia de lo que las demás piensen de ellas? ¿No debemos exigir que las ideas y los procedimientos que dan sentido a la vida de las personas se admitan como miembros de pleno derecho de una sociedad libre con independencia de lo que las demás tradiciones piensen sobre ellos? ¿Queremos conceder a la falsedad los mismos derechos que a la verdad? ¿Queremos que se tome a los sueños tan en serio como a las descripciones de la realidad? (1982, p. 87).

En este sentido, la educación científica en abierta oposición a la pluralidad de los saberes, impone al individuo un conocimiento fragmentado, sesgado y en serie, que le impide la comprensión del saber respecto a las dinámicas y circunstancias de la vida social. La educación científica se constituye en una forma de intervención de la conducta humana que pretende la reproducción interminable de estereotipos. El individuo se somete entonces al sistema científico y a sus patrones de homogenización, y con ello, el pensamiento productivo y creativo individual se reduce a la mera futilidad de la vida y al carácter efímero del tiempo humano. El proceso uniforme que se impone al hombre ya no es el de la vida y de sus múltiples saberes, sino el de la técnica: la vida como natalidad, imaginación y padecimiento del ser en la absolutez del saber es sustituida por la fabricación, planeación y ejecución artificial del mundo. La enseñanza del saber cada vez más elevada y continua en el tiempo como desarrollo de las potencialidades constitutivas de la subjetividad individual ha sido desplazada por la simplificación de los conocimientos teóricos en virtud de los requerimientos de la ciencia. Según Michel Henry (2006), los saberes técnico- 
científicos han sustituido los saberes fundamentales del desarrollo teórico y práctico para todo acto de vida: filosofía, arte, literatura, teología, lenguas, historia, derecho. Estos saberes prácticos respecto a la vida, a diferencia de los técnicos-finalistas, permiten dirigir la mirada a los modos de construcción, comportamientos, usos y rituales de los hombres. En todo caso, permiten recordar aquellos actos creativos y trascendentales de la acción humana en el mundo, así como esperar un acto siempre nuevo y emancipador de la pluralidad humana.

La propuesta de Feyerabend, nos permite entonces combinar distintas formas de comprensión del mundo social, a partir de su pluralidad y complejidad. Con ello podemos afirmar la existencia de una sociedad libre y democrática en virtud de sus distintas cosmovisiones, creencias y prácticas de vida. El individuo se encuentra aquí en mejores condiciones de defender la forma de vida más querida por él, ya que las personas pueden pensar y vivir con plena independencia y, finalmente, soñar e imaginar el sentido de sus vidas sin las imposiciones de otros. El ciudadano en una sociedad libre de toda ideología, incluida la de la ciencia, tiene pleno derecho a leer, escribir y promover cuanto despierte su fantasía. Y no sólo tiene el derecho individual a aceptar las ideas, vivir de acuerdo con ellas y divulgarlas en cuanto ciudadano, sino que puede formar asociaciones para defender su punto de vista (Feyerabend, 1982, pp. 88-99). Según Feyerabend, esta posibilidad del ciudadano en una sociedad libre se admite por dos razones: primero, porque todo el mundo debe poder buscar lo que crea que es la verdad o la forma correcta de actuar; y segundo, porque el único modo de llegar a formarse una opinión útil de lo que se supone es la verdad o la forma correcta de actuar consiste en familiarizarse con el mayor número posible de alternativas. La sociedad libre es por supuesto una sociedad más humana, ya que rehabilita la capacidad de los individuos por imaginar otras formas de vida no científicas, sino formas reales de vida de otros individuos o sociedades que no conoce ni conocerá en un tiempo próximo.

El anarquismo epistemológico se reconoce en la pluralidad de métodos y herramientas para estimular la libertad de pensamiento y utilizarla al máximo: "no como vía de escape, sino como un medio necesario para descubrir y quizás incluso cambiar las propiedades del mundo en el que vivimos" (Alsina, 1986, p. 25). Esta pluralidad de métodos y herramientas involucra al mismo tiempo una multiplicidad de formas de expresión humana en relación con la vida, tales como: la pintura, el cine, la literatura. Estos tipos de expresión nos permiten ampliar la percepción que tenemos del mundo a partir de la imaginación activa no sólo de nuestros propios espacios, sino de otros lugares y realidades. El individuo experimenta el deseo por descubrir otras realidades que escapan a la regularidad de su propio conocimiento. De manera que la imaginación se presenta como una posibilidad de comprender otras maneras de entender el mundo: la formación de mitos, la creación de conjeturas y puntos de vista inusuales, el curso deliberado de la propia vida, a partir de estilos y modos creativos de habitarla, conducen indefectiblemente a una libertad mayor que aquella que provee el mando de las mayorías sociales. De la imaginación que crea y 
transforma la vida del cuerpo individual y colectivo proviene el fundamento lógico de la sociedad libre pretendida por Feyerabend (1982):

La libertad. La imaginación permite la multiplicación de ideas, cosmologías y estándares sociales que conducen a la confrontación y la crítica de los presupuestos de autoridad que dominan las maneras de comprender el mundo de la vida. La imaginación en la sociedad libre estimula otras formas alternativas y proliferantes que aseguran la autonomía de los individuos y ciudadanos del cuerpo social. En suma, la imaginación se opone a aquella educación mecánica y repetitiva que impide el ejercicio creativo y transformador del pensamiento. Esta realidad es contraria, por supuesto, a la educación escolar en la que el estudiante se enfrenta a copias disecadas y falsificadas de viejas decisiones (p. 99).

El anarquismo epistemológico también nos incita a recrear otros espacios y formas de vida surcadas por el dolor de la guerra, la exclusión, el abandono. Porque la propuesta de Feyerabend, es útil no solamente para la educación de "ciudadanos libres" en sociedades "normales", sino también, y, con mayor razón, en sociedades "excepcionales" como la nuestra. La imaginación nos permite aquí desplazar otras teorías y categorías capaces de responder a los problemas de nuestro tiempo: la historia de Occidente $\mathrm{y}$, en particular, la historia de Colombia, nos implica justamente la más alta creatividad y agudeza para recrear otras reflexiones que se distingan de las meras explicaciones causales de los acontecimientos. En materia de educación jurídica, la responsabilidad es, pues, mayor a la simple actualización de los currículos. Cada vez se hace más necesario sustituirlos métodos abstractos con pretensión de universalidad e imparcialidad por métodos más abiertos que intenten comprender y actualizar las categorías del derecho a partir del diálogo con el cine, la poesía, la política, la historia, la literatura. Las respuestas jurídicas basadas en la mera analogía sucumben irreflexivamente ante los acontecimientos de guerra y devastación que bordean a nuestras sociedades: ¿Cómo explicar jurídicamente las causas reflexivas del hombre irreflexivo; la confesión de lo inconfesable; el perdón de lo imperdonable; la tasación del castigo de lo desmedido e insuperable; la prescriptibilidad de lo imprescriptible; la reparación de lo irreparable; la repetición incesante de lo irrepetible? Esta propuesta epistemológica constituye, pues, un programa de reforma a la enseñanza del derecho, al contradecir la supuesta neutralidad del derecho en su relación con la política, la ideología y la sociedad. En términos de Kennedy (2012), debemos hacer del "aula un lugar donde los alumnos aprendan doctrina y argumentación jurídica en el proceso de autodefinirse como actores políticos en sus vidas profesionales" (p. 71).

La educación jurídica en nuestro contexto nos demanda la realización de un ejercicio vivo y dialogante que, más allá de la simple y mecánica repetición de reglas, nos permita deconstruir críticamente los juicios de verdad que hemos heredado de teorías foráneas como el positivismo puro del que se ha servido del pensamiento más conservador y recalcitrante. En este contexto, los estudios de derecho no pueden 
seguir perpetuando los discursos del statu quo respecto a la realidad social, ya que impiden establecer un ejercicio crítico y renovado de nuestras teorías y nociones de pensamiento. Debemos procurarles a los estudiantes otras concepciones del derecho a fin de que puedan transformar la sociedad en virtud dela justicia, la equidad y la solidaridad. Aquí puede ayudarnos la anarquía epistemológica y su metodología pluralista como una forma de hacer proliferar otras ideas más acordes con la actualidad y, por consiguiente, más capaces de transformar las estructuras estáticas de enseñanza jurídica por unas más humanas y sociales.

\section{EL CINE Y SU FUNCIÓN PRAGMÁTICA EN LA ENSEÑANZA E INVESTIGACIÓN JURÍDICA}

El cine es, quizás, el mejor medio para comprenderla relación del derecho con realidades sociales actuales, ya que nos permite entender las fluctuaciones esenciales de la guerra, la revolución, la democracia, la exclusión. El cine tiene como paisaje la tierra, las ciudades, los barrios; permite descubrir otros espacios y situaciones a partir de la más aguda afectación de lo representado. Nos educa para descubrir aquello que, aunque incluido en el espacio que cotidianamente habitamos, se sustrae indiferentemente a la vista: la mirada, en principio desinteresada, comienza paulatinamente a capturar el momento justo en que aparece el acontecimiento de la guerra, el dolor, la exclusión. La mirada exige al espectador la más alta sensibilidad, solidaridad y respuesta reflexiva ante los otros: ese hombre que tiene un rostro, un nombre, es un ser vivo, un individuo que mora el mundo de la vida con los suyos que también son individuos con sus rostros y sus nombres. Los individuos son más que números abstractos de una ficha o un expediente judicial: son hombres cuyas preguntas trágicas comparte el espectador: ¿Quién soy? ¿Por qué vivo? ¿Qué sentido tiene todo esto? El cine dota de significados los espacios, los personajes y las circunstancias de hombres y lugares reales pero ocultos, a fin de disponer al espectador a distintas comprensiones ante lo representado. El cine hace presente la ausencia a la mirada: lugares invisibles, lugares periféricos de la sobrevivencia que, no obstante, coexisten con la vida colectiva. Otros espacios habitados por los muertos y los sobrevivientes que yacen en el olvido y en el silencio. Lugares diferentes a los propios habitados por los viejos y las madres solas; lugares de la humillación y la anulación en continua propagación que, aunque localizables, siempre están excluidos en el desarraigo, la desaparición y la pobreza. Estos espacios representados en las imágenes del cine son los mismos que encontramos en las ensimismadas urbes en crecimiento habitadas por aquéllos desposeídos cuyos nombres engrosan los anaqueles históricos y judiciales.

El cine nos muestra lugares efectivos y reales habitados por la muerte y el dolor, la aniquilación y la agonía de la guerra y la exclusión. El cine hace borrosas nuestras fronteras entre lo visto y lo no visto, entre lo real y lo aparente, entre la percepción y la ficción, entre el hombre y el no-hombre. Nos permite el contagio solidario del otro evocado como compañero de sufrimiento y humillación, puesto que nos implica la 
común identidad del dolor en la contingente e inminente posibilidad del desamparo por venir. El espectador puede verse vivir en el otro mientras comprende su fragilidad. Desde el "nosotros" la imaginación se inquieta siempre por el otro: ¿Quién es aquél que pregunta por la cuestión originaria del sentido de la vida? ¿Quién es aquel que se pregunta por sí mismo? ¿Quién es él? ¿Por qué vive? ¿Qué dice de él en el acto de preguntar? ¿Quién era él y quién es ahora? ¿Quién es el hombre que se disuelve en la fragmentación de la humillación y el sufrimiento? ¿Ese es el rostro borroso y sin duelo de la guerra sin fin, de la pérdida continua que promete la destrucción del hombre? ¿Quiénes somos los que preguntamos por aquel compañero cuya ausencia cruel lo hace invisible a nuestra mirada? Estas preguntas gestadas en el movimiento activo de la imaginación nos permiten subvertir la evasión del otro, capacitando su aparición con rostro visible y semejante al "nosotros". Este movimiento de la imaginación desplaza el mundo invisible a la evidencia de la reflexión que nos recuerda nuestra común condición de humanidad. La representación artística constituye justamente el testimonio de la barbarie, pero también de la esperanza por lograr una comunidad emocional que rememore el pasado, juzgue el presente y consolide un futuro justo. Aquí reside más exactamente la función del cine: en afectar al espectador con relación a lo representado, lo cual no se agota únicamente en la belleza, sino también en la repugnancia, el ridiculo, la vergüenza, la piedad frente a los acontecimientos.

En el cine podemos ver a una madre bañada en lágrimas ante el ataúd de su hijo mientras eleva impotente sus brazos; desfiles de ataúdes; casas incendiadas por las masacres; cadáveres destrozados; desterrados sin futuro; asesinos impunes; prisioneros y torturados. Estas representaciones revelan al mismo tiempo las expresiones y emociones más humanas: rostros descompuestos, ojos enrojecidos, manos crispadas o entrelazadas, figuras postradas y actitudes suplicantes que descubren la tristeza, la esperanza, la agonía, el ruego, la compasión, el dolor. Aquí el cine nos permite dirigir una mirada compasiva, exacerbada y solidaria dotada del más alto sentimiento político y ético, y nos ofrece un testimonio personal y social ineludible hasta para el más indiferente, a fin de que se no olviden aquellas vidas que han sido sesgadas por la barbarie. El cine confía en que el espectador sea un testigo que logre interpretar los acontecimientos y transformar su relación con el mundo. Como ejercicio del pensamiento aspira a la resignificación de la vida por medio de la respuesta emocional del espectador: una obra sobre los desterrados en Colombia, por ejemplo, debe llevarnos no sólo a un cambio en la manera de verlos, escucharlos y tratarlos, sino también a revisar las alternativas que superen las causas históricas del destierro. Si la obra es capaz de producir este efecto, es decir, si logra que los espectadores vean las injusticias e inequidades donde antes permanecían ciegos e indiferentes a ellas, es artística y educativamente excelente. Las experiencias humanas del amor y el dolor, la belleza y el terror, la esperanza y el sufrimiento, la donación y la humillación implican la más aguda afectación a la subjetividad del espectador. Las imágenes proyectadas en el cine constituyen una entre varias maneras en que 
los actos de belleza o crueldad de la obra se presentan a la sensibilidad humana despertándola a la inminente necesidad de la acción y la transformación. Y estas afectaciones que logra el cine permiten entender las razones de su importancia para la vida humana $\mathrm{y}$, al mismo tiempo, las razones para reservarle un espacio en la educación.

Pese a que las imágenes han sido juzgadas en términos meramente semánticos respecto a aquello que representan, tienen una fuerte relación con la pragmática. La imagen embellecida es claramente pragmática: tiene por objeto que los espectadores se sientan más atraídos por aquellas cosas o personas que le muestran los agentes embellecedores. La belleza, como modulador, al igual que la repugnancia y la indignación, hacen que el espectador sienta la atracción o aversión ante el acontecimiento. Según Artur Danto (2005), la emoción adecuada procura una mejor interpretación de los hechos sociales, en tanto las emociones aumentan la potencia de nuestro pensamiento. La afectación del espectador y su consecuente disposición para la acción adquiere una especial relevancia en la educación jurídica, ya que el estudiante reunirá comprensiones más complejas sobre los hechos sociales que posteriormente soportarán las razones de sus juicios y decisiones en justo derecho. El cine constituye una propuesta desde la epistemología anarquista y los currículos alternos, en tanto favorece modos de pensar más heterodoxos, abiertos y humanos. Se sirve más de los sentimientos y la imaginación que de los cálculos de la razón para comprender la realidad. La afectación artística, en términos de belleza, indignación y repugnancia, son condiciones necesarias para una educación que se pretende ética, jurídica, política e histórica en tiempos de oscuridad y de barbarie: las imágenes no deben estar aisladas de la educación. Forman parte de la misma bajo esquemas más amplios que la simple reproducción mecánica e irreflexiva de las normas positivas, por la sencilla razón de que el cine como pensamiento en imágenes es inseparable del resto de la vida.

Bajo estas consideraciones, la Facultad de Derecho de la Universidad Santo Tomás Sede Medellín, propuso la creación de un espacio educativo e investigativo a partir del cine con miras a pensar en algunos problemas sociales derivados de la exclusión y la barbarie. Nuestro interés reside en proponer la proyección de algunos ciclos de cine orientados a estimular la imaginación y el pensamiento libre y solidario de nuestros estudiantes con relación a otros seres humanos y circunstancias. Los ciclos propuestos son: 
Figura 1. El niño del pijama de rayas

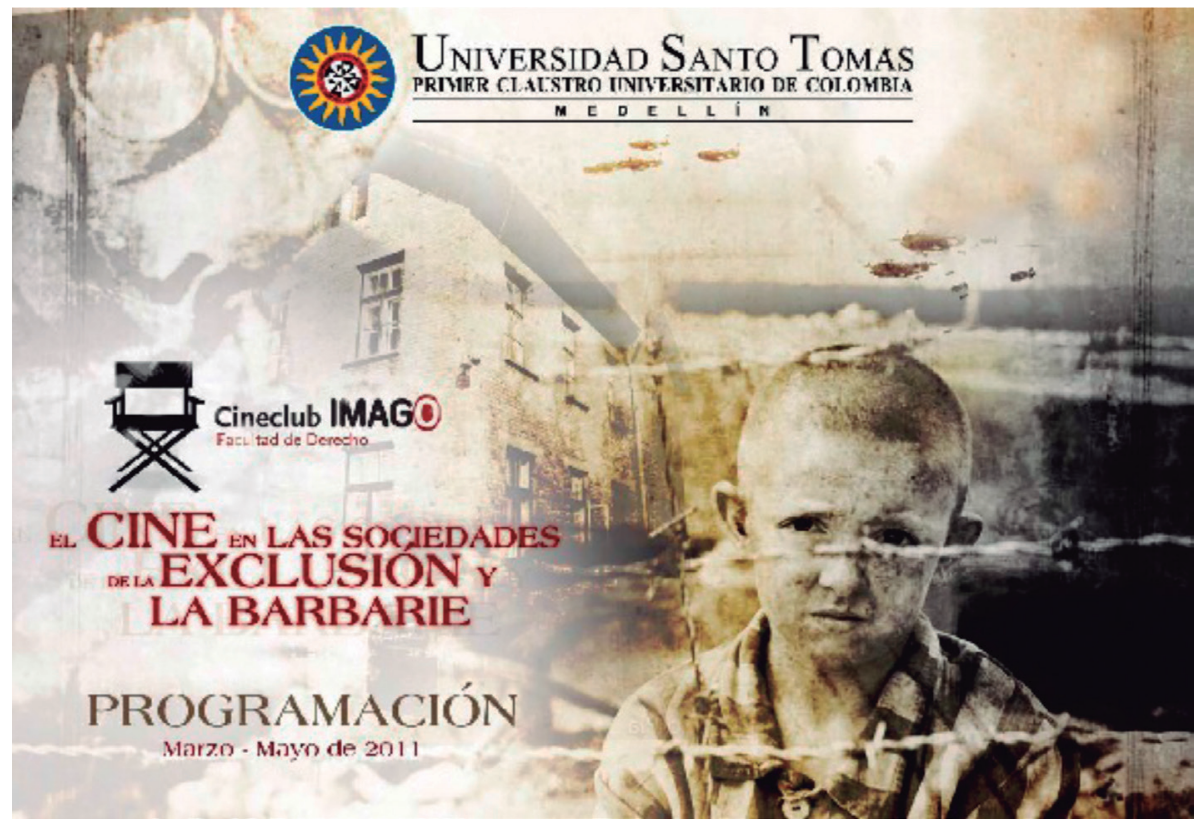

Fuente: Diseñado por Deibyd Pérez (2011)

\section{CICLO: "LOS JURISTAS DEL HORROR"}

Este ciclo está inspirado en el texto de Ingo Müller (2009) "LosJuristas del Horror", en el cual se examina cómo en los médicos y en los juristas nazis recaía la responsabilidad de matar a centenares de seres humanos que estaban asociados con algún tipo de incapacidad física, mental, moral y antisocial. En el nacional socialismo se revela, en efecto, el poder soberano del Führer para matar y, al mismo tiempo, el biopoder gestionado por la medicina. Pero esta complicación entre la profesión jurídica y la médica respecto a la idea de matar a las personas que constituían un peligro para la raza, es anterior al nazismo. En 1920, el jurista alemán Karl Binding y el psiquiatra Alfred Hoche habían escrito un texto titulado Autorización para destruir las vidas de quienes no merecen vivir (Die Freigabe der Vernichtung lebensunwerten Lebens). Al iniciar la segunda guerra, esta idea empezó a practicarse en el Estado nazi mediante el Programa T-4 de Eutanasia. En principio, los pacientes indignos de vivir asignados a los hospitales públicos fueron trasladados a otras instituciones $\mathrm{y}$, posteriormente, asesinados con inyecciones o cámaras de gas. Posteriormente, el programa de muerte masiva fue legalizado en virtud de un decreto del Führer, en el cual se autorizaba sin ninguna reserva dicho proyecto. Este programa permaneció 
activo oficialmente hasta 1942; sin embargo, continuó operando extraoficialmente hasta el final de la guerra asesinando miles de personas (Müller, 2009, pp. 187-189).

Los campos de concentración y de Estado (StaatlicheKonsentrationslager) se apoyaban en la base jurídica de la custodia protectora a fin de salvaguardar la seguridad del Estado. En principio fueron creados como espacios adicionales de concentración debido al aumento de prisioneros en penitenciarías y cárceles. Durante 1933 se construyeron los primeros Campos de Emsland —en el distrito de Emsland y el condado de Bentheim - , que incluían los de Borgemoor, Esterwegen y Neusüstrum, en los cuales se recluyó a cuatro mil prisioneros políticos-intelectuales de origen alemán (Müller, 2009, p. 135). Posteriormente, el sistema concentracionario se amplió complejamente mediante la creación de otros campos de concentración, trabajo y exterminio. Estos campos fueron abiertos para los extranjeros, y las razones de seguridad que antes animaban su constitución fueron modificadas por razones económicas. Por eso los campos de prisioneros cedieron su paso a los campos de trabajo y exterminio. Los detenidos debían trabajar para distintas empresas, bien fueran de propiedad de las S.S o bien fueran de propiedad privada. Los cuerpos de los prisioneros también sirvieron para que los nazis, en asocio con distintas firmas farmacéuticas, efectuaran todo tipo de experimentación médica: ablación de los músculos, castración y esterilización, creación de llagas infectadas, quemadura por aplicación de fósforo, entre otras (Federación Nacional de Deportados e Internados Resistentes y Patriotas, 2005, p. 128). Finalmente, los detenidos morían debido a las duras condiciones o eran exterminados por medio de las ejecuciones, las cámaras de gas o los centros de eutanasia.

Las películas presentadas muestran precisamente los dispositivos,las reglamentaciones, las burocracias e instituciones del fascismo alemán que hicieron posible la muerte administrada y en serie de millones de seres humanos. Se proyectaron los siguientes filmes:

\section{La rosa blanca (The white rose)}

Director: Marc Rothemund

(Alemania, 2005)

Duración: 95min

El lector (The Reader)

Director: Stephen Daldry

(Alemania / EE.UU., 2008)

Duración: 124 min. 


\section{De entre las cenizas (Out of the ashes)}

Director: Joseph Sargent

(EE.UU., 2003)

Duración: 108 min.

\section{Eichmann (Eichmann)}

Director: Robert Young

(Hungría, 2007)

Duración: 100 min.

\section{CICLO: "NUDA VIDA"}

Este ciclo intenta desarrollar el concepto de nuda vida (bloß Leben) utilizada por Walter Benjamin en su texto "Para una crítica a la violencia” (1927), para referirse a aquella vida humana que se encuentra sometida a la violencia del poder. El filósofo italiano Giorgio Agamben prolonga esta expresión hasta la imagen del musulmán. Según Agamben, en el momento en que el internado de los campos de concentración se convierte en cadáver viviente, la biopolítica del racismo se extiende más allá de la raza y penetra en un umbral en el que ya no cabe establecer cesuras. En este punto, el poder de disposición sobre la nuda vida se transforma en un poder de producción en masa de sobrevivientes (2005, p. 89). Este proceso de producción de cadáveres vivientes se logra, justamente, debido a la combinación efectiva, casi ininteligible, entre el viejo poder soberano de matar acompañado de sus poderes normativos, de sus guardias e instituciones disciplinarias, y del moderno biopoder de regularización de la vida colectiva, con sus procesos de medicalización y de control demográfico, sanitario, nutricional, etc. El no-hombre, el muertoviviente revela pues la co-implicación de los distintos modelos de poder que se expresan mediante la aplicación extraordinaria de la fuerza sobre la nuda vida.

En Benjamín, la sangre simboliza la nuda vida que es usufructuada, y al mismo tiempo, aniquilada por la violencia del derecho. Pero más allá de esta forma del poder soberano, nuestro tiempo ha demostrado que el biopoder contemporáneo reduce la vida a la sobrevida biológica, produce sobrevivientes. La sobrevida del homo sacer constituye en su forma última el símbolo del poder de matar. Pero es precisamente porque el muerto-vivo excede los campos de concentración alemanes, y porque se lo encuentra ya en la creciente masa de desarraigados, marginales, desposeídos y anónimos que deambulan por las ciudades del mundo, que el poder jurídico-político ya no tiene necesidad de matar a través de las armas, pues logra hacerlo con igual eficacia mediante el empobrecimiento, el hacinamiento, el hambre y el abandono: todo 
aquello que conduce a la sobrevivencia biológica del hombre hasta su agotamiento, y finalmente, su aniquilación. "De Guantánamo a África, eso se confirma día tras día" (Pelbart, 2009, p.36). En palabras de Agamben (2005), ahora "lo que está en juego es, pues, seguir siendo o no un ser humano, convertirse o no en un musulmán” (p. 56).

Para desarrollar la expresiónde nuda vida nos servimos especialmente - aunqueno exclusivamente - de películas del neorrealismo italiano, que fue un movimiento cinematográfico surgido en la segunda posguerra mundial en Italia (1945-1947), y cuyos principales representantes fueron Roberto Rosellini, Luchino Visconti y Vittorio de Sica.El neorrealismo se caracteriza por mostrar la vida de los sectores más pobres y sus sentimientos más profundos: tristeza, desesperación, angustia. El aspecto central de este movimiento cinematográfico consistió precisamente en evidenciar la realidad en toda su desnudez, a fin de mostrar los efectos de la guerra y el fascismo en la vida social. Este cine se convirtió en un instrumento de denuncia sobre los problemas sociales en tiempos de una fuerte depresión económica y moral en Italia, a saber: negación de las pensiones, falta de vivienda, discriminación a la mujer, violencia sobre los niños y niñas (Hincapié y Otalvaro, 2009, p. 24). Las películas presentadas fueron las siguientes:

\section{La infancia de Iván (Ivanovo Detstvo)}

Director: Andrei Tarkovski

(Rusia, 1962)

Duración: 95 min.

\section{Alemania año cero (Germania anno zero)}

Director: Roberto Rossellini

(Francia/Alemania/Italia, 1947)

Duración: $75 \mathrm{~min}$.

\section{Roma, ciudad abierta (Roma città aperta)}

Director: Roberto Rossellini

(Italia, 1945)

Duración: 98 min.

\section{El ladrón de bicicletas (Ladri di biciclette)}

Director: Vittorio De Sica

(Italia, 1948)

Duración: $92 \mathrm{~min}$. 


\section{Umberto D (Umberto D)}

Director: Vittorio De Sica

(Italia, 1952)

Duración: 89 min.

El niño con el pijama de rayas (The boy in the striped pyjamas)

Director: Mark Herman

(Reino Unido/Estados Unidos, 2008)

Duración: 94 min.

Figura 2. Frankenstein

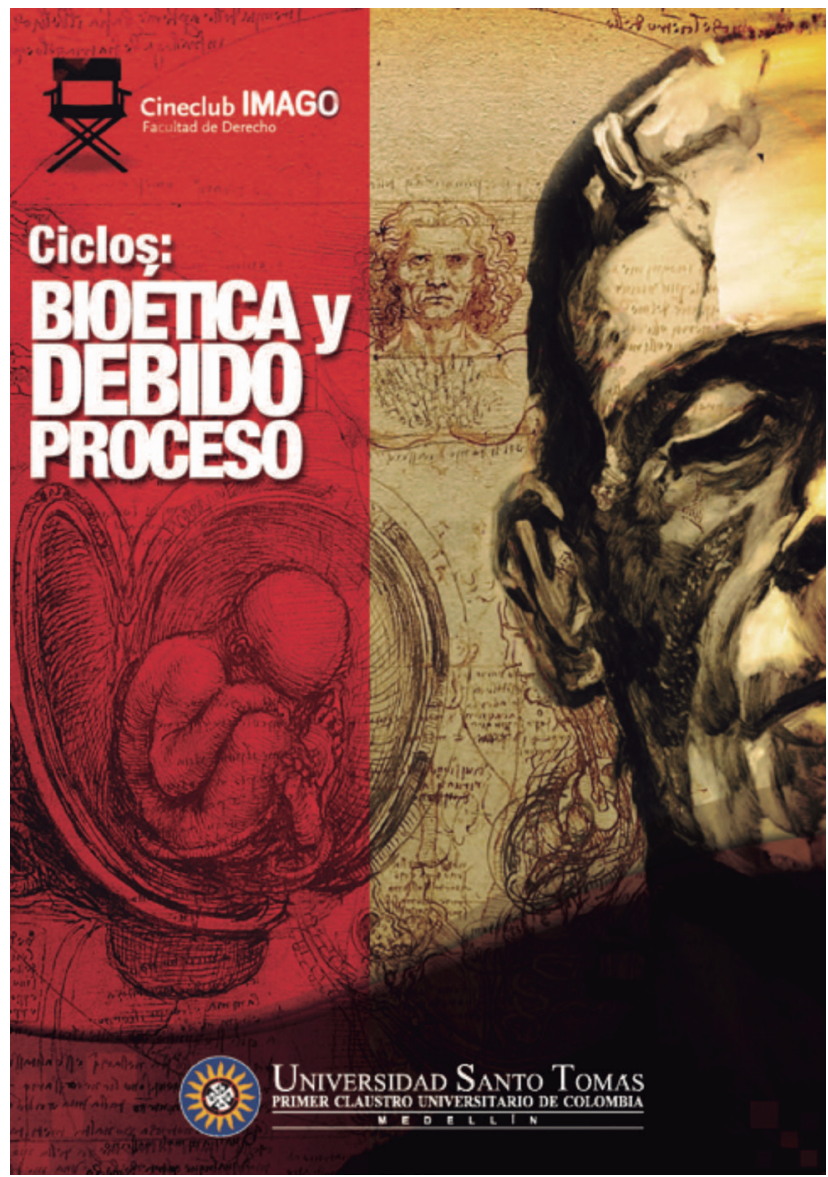

Fuente:Diseñado por Deibyd Pérez (2012) 


\section{CICLOS: "BIOÉTICA" Y "DEBIDO PROCESO"}

Con estos ciclos pretendimos establecer la co-implicación de dos campos disciplinares en directa relación con los debates contemporáneos sobre el derecho y la vida: la bioética y la biopolítica. El primero se remonta a su fundación por el oncólogo V. R. Potter, en la década de 1960; el segundo se origina una década más tarde en el marco de los cursos de Michel Foucault, principalmente en Seguridad, territorio, población, y El nacimiento de la biopolítica. El campo de la bioética aparece y se desarrolla como un campo en disputa, por lo menos para sus tres más notables vertientes: la bioética médica, que es la vertiente dominante por haberse erigido sobre la base que le proporcionaron los tribunales hospitalarios; la bioética de vertiente teológica, más conservadora en la medida en que establece límites al saber médico y a las decisiones jurídicas en materia de la vida y la muerte; y la bioética de inspiración laica asociada con el saber jurídico. Fácilmente se reconoce que esta disputa evoca el "conflicto de las facultades superiores" que componela estructura canónica de la Universidad. De ahí que la bioética aparezca como un campo interdisciplinar: se trata de un campo de intersección en el que se cruzan intereses sobre la vida corporal, política y moral de las sociedades contemporáneas. Por eso no es extraño que dicho saber haya ido adoptando la forma de una principialística, de una axiomática o de una dogmática, análogas a la del derecho, la medicina y la teología, pues de alguna manera ofrece una síntesis de dichos saberes. Su asunto es, pues, el de un caso de litigio ya que de allí se desprenden consecuencias prácticas en el cuerpo mismo de las personas, las sociedades y la especie.

La biopolítica, por su parte, al menos en la descripción de Foucault, se define por un ejercicio estratégico y político del poder sobre la vida, en todas sus dimensiones. Se trata de un conjunto de discursos y prácticas que tienen su origen en el poder soberano, que se ejercita sobre todo como derecho de matar, mediante la fórmula de hacer morir y dejar vivir, la cual se transforma progresivamente en hacer vivir $y$ dejar morir, que hace de la apropiación de lo biológico y del cuidado de la nuda vida su objetivo primario. La biopolítica surge aquí como este conjunto de estrategias orientadas a gestionar y administrar la vida de las poblaciones. Para ello se adoptan saberes como la estadística, los controles al abastecimiento alimentario, la prevención del riesgo, las vacunas, los controles de natalidad, morbilidad, etc., todo ello en una oscilación constante entre lo previsible y lo controlable, mediante un control abierto, distinto al de las sociedades disciplinarias que funcionaban mediante dispositivos de encierro. La biopolítica caracteriza el gobierno de las sociedades contemporáneas, organizadas en formas de vida metropolitanas. Uno de sus rasgos determinantes es, sin duda, el del mantenimiento de una axiomática de la seguridad, que produce el tipo de organización a la que por su parte Gilles Deleuze (2006) le da el nombre de sociedad mundial de control. 
Este ciclo propone, justamente, la reflexión sobre la bioética y la biopolítica a partir de distintos fenómenos sociales que coexisten en la contemporaneidad: desde la medicalización, la experimentación y la manipulación propios de las sociedades del control, hasta el encierro y la decisión sobre la vida y la muerte que permanecen vigentes en las sociedades modernas de la disciplina y de control. Para ello, se inicia con películas sobre la experimentación en el cuerpo humano que pasa por la medicalización y la intervención. Se concluye con películas sobre la industria farmacéutica, los sistemas de aseguramiento de la salud, la mercantilización de la vida de las personas, la manipulación de la raza como fenómenos que hacen gravitar al saber bioético entre las estrategias biopolíticas contemporáneas.

Seguidamente, se desarrolló un ciclo sobre el debido proceso para mostrar el más puro y aterrador ejercicio del poder del soberano a partir de los procesos de burocratización del derecho, el cual concluye en la pena de muerte. Ésta testimonia la violencia del más fuerte que es capaz de hacer del hombre una cosa en el sentido más literal, pues hace de él un cadáver.Las películas presentadas fueron las siguientes:

\section{Ciclo: Bioética}

\section{La mosca (The Fly)}

Director: David Cronenberg

(Estados Unidos, 1986)

Duración: $95 \mathrm{~min}$.

\section{Frankenstein, de Mary Shelley}

Director:Kenneth Branagh

(Reino Unido, Estados Unidos, Japón, 1994)

Duración: 123 min.

\section{Gattaca}

Director: Andrew Niccol

(Estados Unidos, 1997)

Duración: 106 min.

Código 46 (Code 46)

Director: Michael Winterbottom

(Reino Unido, 2003)

Duración: 92 min. 


\section{Sicko}

Director: Michael Moore

(Estados Unidos, 2007)

Duración: $90 \mathrm{~min}$.

Al cruzar el límite (Extreme D'Measures)

Director: Michael Apted

(Estados Unidos, 1996)

Duración: 114 min.

El jardinero fiel (The constant gardener)

Director: Fernando Meirelles

(Reino Unido, Alemania, 2005)

Duración: 129 min.

Las invasiones bárbaras (Les invasions barbares)

Director: Denys Arcand

(Francia, Canadá, 2003)

Duración: $99 \mathrm{~min}$.

\section{Ciclo: Debido proceso}

Doce hombres en pugna (12 angry men)

Director: Sidney Lumet

(Estados Unidos, 1957)

Duración: $96 \mathrm{~min}$.

\section{Legítima defensa (The Rainmaker)}

Director: Francis Ford Coppola

(Estados Unidos, 1997).

Duración: 135 min. 
El proceso (Leprocès)

Director: Orson Welles

(Francia, Italia, Alemania, 1962)

Duración: 118 min.

Expreso de medianoche (Midnight Express)

Director: Alan Parker.

(Reino Unidos, Estados Unidos, 1978)

Duración: $121 \mathrm{~min}$.

En el nombre del padre (In the name of the father)

Director: Jim Sheridan

(Reino Unido, Irlanda, 1993)

Duración: 133 min.

\section{Salvador}

Director: Manuel Huerga

(España, 2006).

Duración: 134 min.

\section{Cuestión de honor (Pride and glory)}

Director: Gavin O'Connor

(Estados Unidos, Alemania, 2008)

Duración: 130 min.

\section{Filadelfia (Philadelphia)}

Director: Jonathan Demme

(Estados Unidos, 1993)

Duración: 125 min. 
Figura 3. Sin titulo

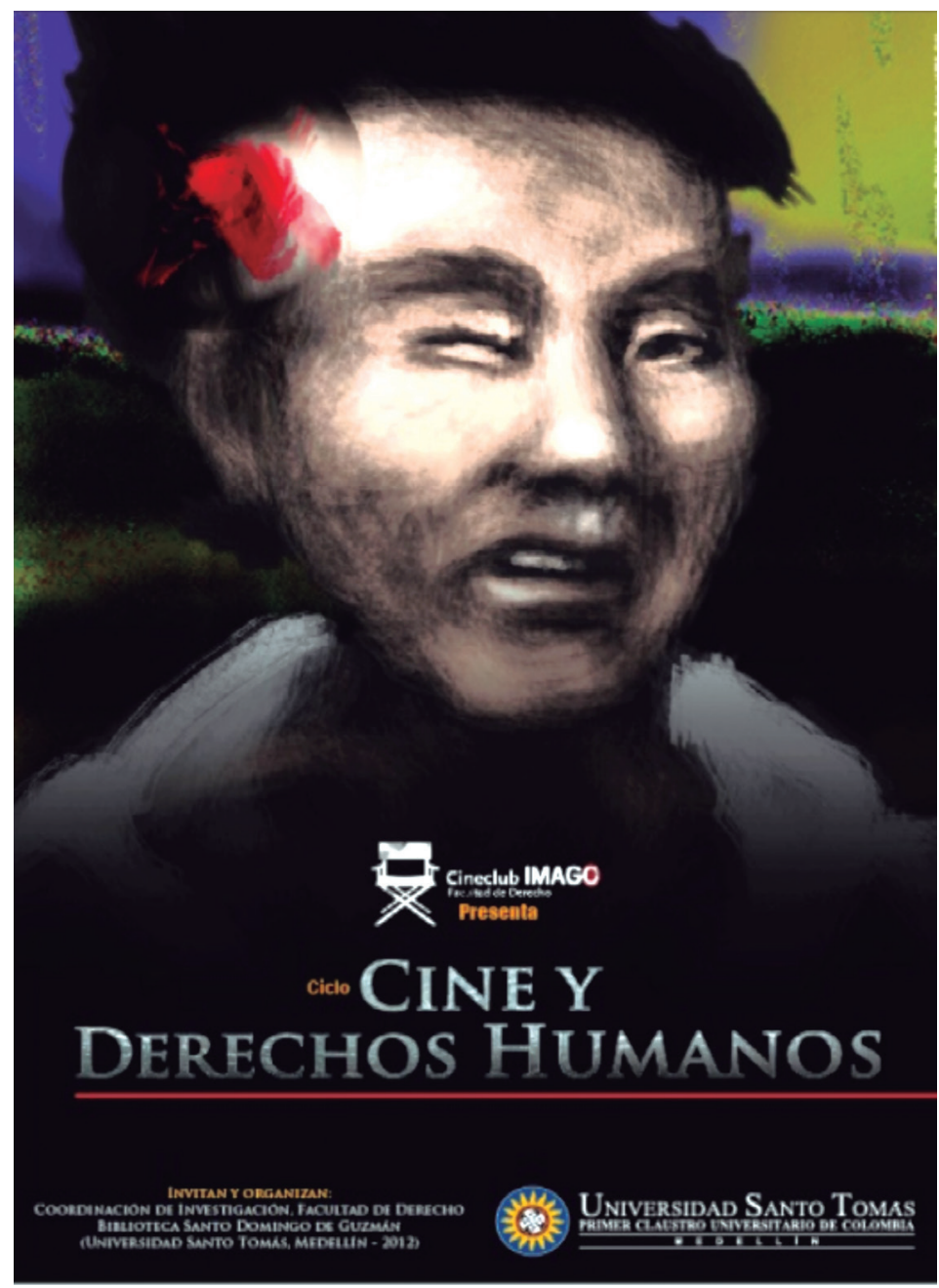

Fuente: Pintura de Martha Zuluaga (1996)

\section{CICLOS: "SENTENCIADO A MUERTE", "LA COLONIA PENITENCIARIA", "DESTERRADOS, REFUGIADOS Y DESAPARECIDOS"}

Estos ciclos se orientan a reflexionar sobre la violencia y el carácter sagrado de la vida humana. Quizá ningún tema de nuestro tiempo resulta más difuso y, al mismo tiempo, más apremiante de tratar que el de la violencia sobre la vida. El asunto de 
la violencia se ha vuelto pues inevitable, ya se trate de la violencia monopolizada por el Estado y las instituciones jurídicas modernas (liberales o totalitarias) y empleada por éstas para mantener la autoridad de las leyes y la consistencia de las instituciones estatales; ya sea que se refiera a la contra-violencia, a la violencia contra la violencia legítima, a la violencia revolucionaria de las fuerzas sociales que se enfrentan al régimen jurídico-estatal dominante en nombre de un Estado alternativo, verdaderamente justo y pacífico. La violencia, en ambos casos, recae directamente sobre la vida; es fuerza que mata haciendo del hombre una piedra, tal como aconteció con Níobe transformada en risco, cuya figura parece llorar cuando los rayos del sol inciden en su capa de nieve invernal, o con Prometeo quien, en la versión contemporánea de Kafka, aguijoneado por el dolor de los picos desgarradores del águila, se fue hundiendo en la roca hasta compenetrase con ella. Pero no sólo en la sangre se revela la violencia sobre la vida, sino que desde siempre se muestran las vidas de hombres y mujeres sometidas a un estado de excepción permanente. Ellos al nacer están destinados a sufrir la violencia de la exclusión, la expulsión, el hambre, el frío. Pero esta fuerza que recae sobre la vida desnuda del hombre, ya no coincide de ningún modo con la vida sagrada. Lo que es sagrado en la vida del hombre no es su mera vida, sino la potencialidad, la posibilidad de la justicia, la justicia de su vida. Su vulneración se refleja claramente en tres condiciones extremas: la del condenado a muerte, la de la vida recluida en los centros penitenciarios, y la de la condición terminal del desterrado, el refugiado y el desaparecido. Las películas presentadas fueron las siguientes:

\section{Ciclo: Sentenciado a muerte}

La vida de David Gale (The Life of David Gale)

Director: Alan Parker

(Estados Unidos, 2003)

Duración: 130 minutos

Pena de muerte (Dead man walking)

Director: Tim Robbins

(Estados Unidos, 1995)

Duración: 120 minutos

Propuesta de muerte (The proposition)

Director: John Hillcoat

(Australia/Reino Unido, 2003)

Duración: 104 minutos 


\section{Salvador}

Director: Manuel Huerga

(España, 2006).

Duración: 134 min.

\section{Monster (Monster)}

Directora: Patty Jenkins

(Estados Unidos/Alemania, 2003)

Duración: $109 \mathrm{~min}$.

\section{No matarás (Zabijaniu)}

Director: Krzysztof Kieœlowski

(Polonia, 1988)

Duración: $84 \mathrm{~min}$.

Ciclo: La colonia penitenciaria

La fuga de Alcatraz (Escape from Alcatraz)

Director: Don Siegel

(Estados Unidos, 1979)

Duración: 112 min.

\section{Papillon (Papillon)}

Director: Franklin J. Schaffner

(Estados Unidos, 1973)

Duración: $150 \mathrm{~min}$.

\section{Homicidio en primer grado (Murder in the First)}

Director: Marc Rocco

(Estados Unidos, 1995)

Duración: $120 \mathrm{~min}$.

El beso de la mujer araña (Kiss of the Spider Woman)

Director: Hector Babenco

(Estados Unidos/Brasil, 1985)

Duración: $120 \mathrm{~min}$. 


\section{Carandiru (Carandiru)}

Director: Hector Babenco

(Brasil, 2003)

Duración: 147 min.

\section{Los hijos de la calle(Sleepers)}

Director: Barry Levinson

(Estados Unidos, 1996)

Duración: 147 min.

\section{Ciclo: Desterrados, refugiados y desaparecidos}

\section{La primera noche}

Director: Luis Alberto Restrepo

(Colombia, 2003)

Duración: $88 \mathrm{~min}$.

\section{Retratos en un mar de mentiras}

Director: Carlos Gaviria

(Colombia, 2010)

Duración: $90 \mathrm{~min}$.

\section{Hotel Rwanda (Hotel Rwanda)}

Director: Terry George

(Estados Unidos/Reino Unido, 2004)

Duración: 110 min.

Disparando a perros (Shooting Dogs (Beyond the Gates)

Director: Michael Caton-Jones

(Reino Unido, 2005)

Duración: 115 min.

\section{Invisibles}

Director: Javier Bardem

(España, 2007)

Duración: $100 \mathrm{~min}$. 


\section{Los niños perdidos de Sudán (Lost boys of Sudan)}

Director: Megan Mylan \& Jon Shenk

(Estados Unidos, 2003)

Duración: $87 \mathrm{~min}$.

Las tortugas también vuelan (Lakposhtha hâm parvaz mikonand)

Director: Bahman Ghobadi

(Irán/Iraq, 2004)

Duración: $95 \mathrm{~min}$.

\section{Nuestramúsica (Notre musique)}

Director: Jean-Luc Godard

(Francia, 2004)

Duración: $79 \mathrm{~min}$.

\section{Desparecido (Missing)}

Director: Costa-Gavras

(Estados Unidos, 1982)

Duración: $122 \mathrm{~min}$.

\section{Estado de sitio (État de Siège)}

Director: Costa-Gavras

(Francia/Italia, 1972)

Duración: 115 min.

\section{El violín}

Director: Francisco Vargas Quevedo

(México, 1998)

Duración: $98 \mathrm{~min}$.

\section{Impunity}

Director: Juan José Lozano \& Hollman Morris

(Colombia, 2010)

Duración: $84 \mathrm{~min}$. 


\section{REFERENCIAS}

Agamben, G. (2005). Lo que queda de Auschwitz. El archivo y el testigo. Homo sacer III (A. Gimeno, trad.). Valencia, España: Pre-textos.

Agamben, G. (2006). Homo sacer. El poder soberano y la nuda vida (A. Gimeno, trad.). Valencia, España: Pre-textos.

Arendt, H. (2009). La condición humana (R. Gil, trad.). Barcelona, España: Paidós.

Benjamin, W. (1991). Para una crítica de la violencia (J. Blatt Weinstein, trad.). Madrid, España: Taurus.

Benjamin, W. (2010a). La reforma escolar, un movimiento cultural (J. Navarro, trad.). en Rodolf Tiedemann y Hermann Schweppenhäuser (Eds.). Obras (1 (Lib. II), pp. 13-16). Madrid, España: Abada editores.

Benjamin, W. (2010b). Romanticismo. Un discurso no pronunciado ante la juventud escolar. (J. Navarro, trad.) en Rodolf Tiedemann y Hermann Schweppenhäuser (Eds.). Obras (1 (Lib. II), pp. 42-46). Madrid, España: Abada editores.

Benjamin, W. (2010c). La juventud y la historia. (J. Navarro, trad.), en Rodolf Tiedemann y Hermann Schweppenhäuser (Eds.). Obras (1 (Lib. II), pp. 60-61). Madrid, España: Abada editores.

Danto, Arthur. (2005). El abuso de la belleza: la estética y el concepto del arte. Barcelona, España: Paidós.

Deleuze, G. (2006). Conversaciones, 1972-1990. Valencia, España: Pre-textos.

Feyerabend, Paul. (1975). How to defend society against science, en Polis: Revista Académica de la Universidad Bolivariana (1), 2001.

Feyerabend, Paul. (1982). La ciencia en una sociedad libre. Barcelona, España: Siglo XXI editores.

Feyerabend, Paul. (1986). Contra el método: esquema de una teoría anarquista del conocimiento. Madrid, España: Ariel.

Foucault, M. (2001). Defender la sociedad (H, Pons, trad.). México: Fondo de Cultura Económica.

Foucault, M. (2004). Vigilar y castigar: nacimiento de la prisión (A. Garzón, trad.). Buenos Aires: Siglo XXI editores.

Henry, M. (2006). La barbarie. (T. Domingo, trad.). Madrid, España: Caparros editores.

Hernández, E. y Barragán, O. Los derechos de los Gobernados. Sé Cauto, 16, 36-69.

Hincapié, G y Otálvaro, C. (2009). Un acercamiento al lenguaje audiovisual. Bogotá:

Libertaria.

Kennedy, D. (2012). La enseñanza del derecho como forma de acción politica (T. Arijón, trad.). Buenos Aires, Argentina: Siglo Veintiuno Editores. 
Müller, I. (2009). Los juristas del horror. La “justicia de Hitler”. El pasado que Alemania no puede dejar atrás (C.A. Figueredo, trad.). Bogotá, Colombia: Álvaro Mora. Librería Jurídica.

Pelbart, P. P. (2009). Nuda Vida, vida besta, una vida. Euphorion, 4, 34-42.

Rorty, R. (1991). Contingencia, Ironía y solidaridad. (Sinnot, A, trad). Barcelona, España: Paidós.

Federación Nacional de Deportados e Internados Resistentes y Patriotas. (2005). 